\title{
Reconstrucción del parcelario histórico de la ciudad de Santander: lectura del sector urbano destruido por el incen- dio de 1941.
}

\author{
Reconstruction of the historical plots of the city of \\ Santander: reading of the urban sector destroyed by \\ the 1941 flood
}

José Miguel ReMOlina SeIVANE

Arquitecto. Associazione Storia della Città (Roma)

jmremolina@coacan.es

Recibido: $10 / 03 / 2017$

Aceptado: 23/07/2017

\section{Resumen}

El presente artículo presenta una reconstrucción de la forma catastral histórica llevada a cabo del sector central de la ciudad, a partir de una reconstrucción crítica del parcelario histórico, especificando las metodologías de estudio, las herramientas disponibles y avanzando algunas interesantes novedades sobre la forma de la ciudad y su evolución histórica que hasta ahora permanecían inéditas.

Palabras clave

Urbanismo, parcelario histórico, Santander, reconstrucción. 


\begin{abstract}
The present article presents a reconstruction of the historical cadastral form carried out of the central sector of the city, from a critical reconstruction of the historical plot, specifying the study methodologies, the available tools and advancing some interesting novelties about the form of the city and its historical evolution that until now remained unpublished
\end{abstract}

\title{
Keywords
}

Urban planning, historical plot, Santander, reconstruction.

Referencia normalizada: REMOLINA SEIVANE, JoSÉ Miguel (2017): “Reconstrucción del parcelario histórico de la ciudad de Santander: lectura del sector urbano destruido por el incendio de 1941". Arte y Ciudad. Revista de Investigación, no 12 (octubre), págs. 185-210. Madrid. Grupo de Investigación Arte, Arquitectura y Comunicación en la Ciudad Contemporánea, Universidad Complutense de Madrid.

Sumario: 1. Introducción. Unos tejidos históricos desaparecidos. El incendio de 1941 2. Lectura de la cartografía histórica. 2.1. Los parcelarios elaborados tras el incendio. 3. Interpretaciones del tejido viario y parcelario en el área intramuros occidental: de Santa Clara a San Francisco. 3.1. Huellas del trazado de la cerca. 3.2. Las huellas de los conventos. 4. Reconstrucción del parcelario y el tejido viario históricos en el área oriental de la puebla. 4.1. Área de la plaza del Príncipe. 4.2. Frente de la Ribera: parcelario. 5. Al norte de la Puebla: Manzana de la Compañía de Jesús, área de la calle San José. 5.1. Traslacava y nueva calle San José. 6. Reconstrucción del parcelario y tejido histórico en área de la cuesta de Gibaja. 7. Conclusiones. 8. Bibliografía.

\section{Introducción. Unos tejidos históricos desaparecidos. El incendio de 1941.}

En los estudios urbanísticos sobre la evolución de las ciudades históricas el análisis del parcelario ha sido siempre una de las herramientas principales a la hora de interpretar formas urbanas complejas. Si en la mayoría de las grandes ciudades europeas se puede contar con planos parcelarios relativamente antiguos que permiten conocer la estructura urbana antes de las grandes transformaciones de la edad Contemporánea, muchas ciudades españolas carecen de tales planos catastrales históricos, dificultando la tarea de interpretación de la forma urbana antigua. 
A falta de esta documentación gráfica, la que ha sido denominada ley de permanencia del parcelario puede ayudar a la reconstrucción del reparto catastral de la ciudad histórica a partir del estudio de las edificaciones actuales; es así que se han llevado a cabo estudios profundos de la transformación de la ciudad a partir de reconstrucciones hacia atrás partiendo del estudio detallado de parcelario actual, con propuestas de interpretación de la estructura catastral antigua ${ }^{1}$.

En ocasiones, sin embargo, ni siquiera esta metodología es posible, especialmente cuando la destrucción provocada por guerras, catástrofes o incendios ha producido cambios radicales, que obliteran las huellas sobre el plano, borrando la traza parcelaria histórica. Tal es el caso de la ciudad de Santander, en que el gran incendio acaecido el 15 de Febrero de 1941 condujo a la desaparición de todo el centro histórico intramuros, que posteriormente fue transformado radicalmente en una rápida reconstrucción que conllevó la alteración morfológica de todo el corazón histórico de la ciudad, fundamentalmente de origen medieval ${ }^{2}$.

Aún a pesar de la avanzada época, la ciudad no disponía de un plano parcelario fiable detallado, hecho que se puso inmediatamente de manifiesto en las fechas posteriores al incendio, obligando a la apresurada realización de planos del parcelario catastral previo al incendio, con la fundamental intención de agilizar los procesos de gestión y reconstrucción del sector destruido.

Esta reconstrucción sobre tablero de una ciudad ya desaparecida resultó sin embargo no del todo satisfactoria; los planos conservados en el archivo municipal presentan distintas simplificaciones, que si bien permitieron el inmediato cálculo de los porcentajes de reparcelaciones, obviaron muchos detalles e irregularidades del parcelario histórico.

El presente artículo presenta una reconstrucción de la forma catastral histórica del sector central de la ciudad, a partir de una reconstrucción crítica del parcelario histórico, especificando las metodologías de estudio, las herramien-

\footnotetext{
${ }^{1}$ Véase entre otros (Passini, 2001); (Cadinu, 2012).

2 Plan de reconstrucción dirigido por Ramiro Sainz Martínez y Rafael Fernández Huidobro, arquitectos, con la colaboración de Sánchez Murélaga y José Fraile, año 1941; (Rodríguez Llera, 1980: 117).
} 
tas disponibles y avanzando algunas interesantes novedades sobre la forma de la ciudad y su evolución histórica que hasta ahora permanecían inéditas.

Para el completo análisis del parcelario se ha considerado imprescindible la elaboración de una planimetría detallada de la ciudad, la que en adelante se denominará Planta reconstructiva del centro histórico 1836-2016, creada para reproducirse a escalas de detalle, $1 / 500$ y 1/250, que permitiera apreciar de modo conveniente los particulares de la evolución urbana de este sector de Santander. La elección de una escala de representación adecuada es de suma trascendencia, pues ha de permitir tanto la representación de aspectos urbanos, apreciándose los trazados generales de calles y conjuntos, como el dibujo en detalle de las arquitecturas más significativas, situándose por lo tanto a medio camino de la escala urbanística y la escala arquitectónica ${ }^{3}$ (Fig.1).

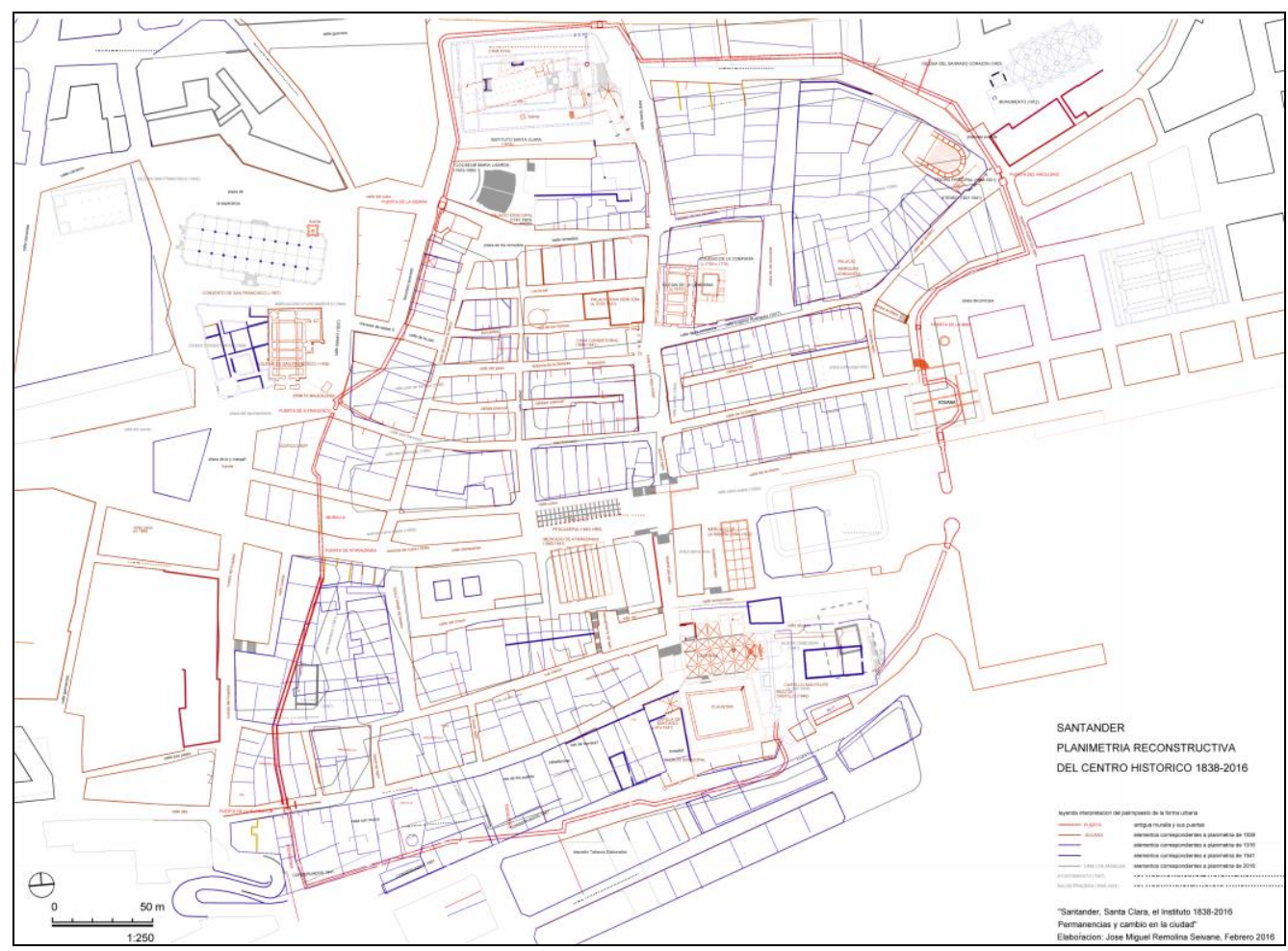

Fig. 1. Santander. Planta reconstructiva del centro histórico 1836-2016. Elaboración del autor.

${ }^{3}$ Acerca de las plantas reconstructivas de la forma urbana, véase (Guidoni, 2006: 11). 
La elaboración de este plano se ha concebido desde la posibilidad que ofrece el dibujo por ordenador de utilizar distintas capas, elaborando un a modo de palimpsesto, en que se dibujan los trazados de calles y los límites de parcelas en el periodo entre 1836 y 1941, ha obligado a resolver algunos problemas de trazado de líneas, poniendo en evidencia algunos datos sobre la reciente evolución de la ciudad que hasta ahora no se habían puesto en evidencia, referidos a determinados lugares o edificios de la ciudad, que sólo ahora cuando son dibujados a una escala de representación detallada dejan en evidencia aspectos que una descripción escrita o de escala general urbana no plantea. Algunos de los aspectos urbanos presentados en el plano están por supuesto aún sometidos a crítica y revisión, presentándose como interpretaciones, revisables ante la presentación de nuevos documentos escritos o gráficos.

\section{Lectura de la cartografía histórica.}

Para la elaboración de la Planta reconstructiva se ha considerado como aspecto fundamental el estudio detallado de las representaciones cartográficas antiguas de la ciudad.

Los documentos más importantes para la reconstrucción de la forma del Santander medieval son los planos realizados por Juan Escofet en 1780 y Agustín de Colosía en 17914. El plano de 1780 de Juan Escofet y Fernando Ulloa forma parte del proyecto de nueva dársena, conociéndose dos planos de interés, ambos fechados en 29 de Abril de 1780; el primero sólo representa parcialmente el conjunto de la ciudad, presentando carencias en la representación de algunos elementos ${ }^{5}$. El segundo plano sin embargo incluye, además del trazado propuesto de la dársena, motivo principal, una representación fidedigna de la puebla nueva, en que se presentan por primera vez con gran detalle trazado de calles, formas de manzanas, muralla, etc ${ }^{6}$ (Fig.2)

El plano elaborado por Agustín de Colosía y publicado en 1791 repite básicamente la mayoría de los elementos presentes en el plano de Escofet, con ligeras variaciones que se irán señalando más adelante ${ }^{7}$.

\footnotetext{
${ }^{4}$ Recogidos en (Martín Latorre, 1998: 82).

${ }^{5}$ Reproducido en (Pozueta Echevarri, 1985: 63,64).

${ }^{6}$ Reproducido con gran detalle en (Martín Latorre, 1998: 76-77)

${ }^{7}$ Recogido en (Pozueta Echavarri, 1985: 151) y reproducido con gran detalle en (Martín Latorre, 1998: 82-83).
} 


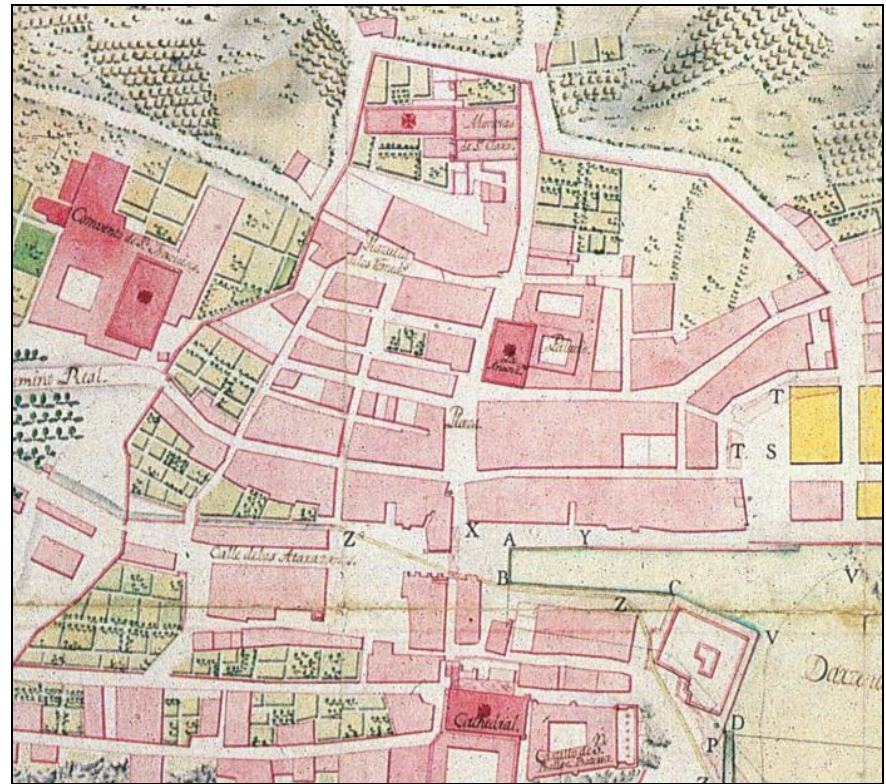

Figura 2. Plano de la ciudad de Santander de Juan Escofet, 1780 (Detalle) (Martín Latorre, 1998: 76. Archivo General de Simancas).

Estos dos planos son documentos imprescindibles para el estudio de la evolución histórica de la ciudad, y si bien han sido repetidamente estudiados, ello ha sido sobre todo para el estudio del crecimiento hacia el este en época ya moderna, y para determinar fases y fechas de la construcción de las estructuras portuarias de la ciudad ${ }^{8}$.

Es preciso señalar ya aquí el hecho de que la mayoría de reconstrucciones del primitivo trazado de la muralla medieval se han realizado a partir de estos planos, destacando de entre las representaciones publicadas la realizada por Casado Soto, publicada en 1990 y la realizada por Aramburu Zabala, publicada en $1998^{\circ}$.

El tercer documento gráfico histórico fundamental es el conjunto de planos elaborado por Joaquín Pérez de Rozas, documento de extraordinario interés. Acerca de este plano tan importante para el estudio de la ciudad de Santander aún no se ha realizado un estudio riguroso; Simón Cabarga señala las vicisitudes de su elaboración mencionando como la documentación presentada al

\footnotetext{
${ }^{8}$ Véase especialmente (Martín Latorre, 1998); (Pozueta Echevarri 1985).

${ }^{9}$ Una primera interpretación se publicó en (Casado Soto, 1990: 27); otra posterior más elaborada en (Casado Soto, 1979: 108); una tercera en (Martín Latorre, 1998: 40).
} 
Ayuntamiento estaba compuesta de un plano a escala 1:5000, 20 hojas a escala 1/1000, 21 hojas de detalle a escala 1/250, y 122 croquis de campo, así como otra documentación complementaria (Simón Cabarga, 2001a: 438). El plano de conjunto ha sido publicado en varias ocasiones ${ }^{10}$, pero las hojas de detalle solo han sido objeto de una publicación parcial (Santander Historia Gráfica, 1984: anexo final).

Es importante señalar el hecho de que este es el primer plano que presenta líneas de nivel, ofreciendo información sobre la micro-topografía del lugar de la Puebla nueva, sector en que las sucesivas reformas alterarán las pequeñas diferencias de nivel, que en épocas tempranas de desarrollo de la ciudad tuvieron fundamental importancia. Tal sucede en la representación de la pequeña elevación situada entre la calle de la Compañía y la calle de la Blanca, representándose la que sería una pequeña elevación, que por situarse dominando las dos dársenas sin duda debió tener importancia en los primeros pasos de la ciudad, y a la que más adelante se aludirá.

Sin embargo ninguno de estos planos representa el parcelario completo de la ciudad; únicamente se representa la línea de división de propiedades en fachada, pero el modo en que estas líneas se prolongan en el interior de la manzana queda sin definir. La única posible reconstrucción debe pues basarse en las indicaciones de límites de propiedades que aparecen en los planos parciales de Pérez de Rozas y en los planos elaborados tras el incendio de 1941.

\subsection{Los parcelarios elaborados tras el incendio.}

El incendio sucedido en Febrero de 1941 supuso la destrucción de un amplio sector de la ciudad, prácticamente todo el área comprendido entre las viejas murallas medievales ${ }^{11}$. A raíz de la catástrofe se elaboraron distintos planos, con el fin de posibilitar la reconstrucción del área en el más breve plazo posible. En el Archivo Municipal se encuentran diversos planos, el más significativo de ellos es un gran plano, sin autoría ni referencia, del que se conserva una fotocopia, doblada, sobre la que se han ido escribiendo diversas anotaciones y datos ${ }^{12}$.

\footnotetext{
${ }^{10}$ Reproducido con gran detalle en (Martín Latorre, 1998: 103).

${ }^{11}$ Descripción y análisis en (Casado Soto, 2001).

12 Plano del que se ha extraído el detalle de la Figura 5. Archivo Municipal de Santander, s/r.
} 
Posteriormente se debieron ir elaborando distintas planimetrías parcelarias de cada una de las manzanas, a medida que se iban realizando las subastas de los solares resultantes de la reparcelación ${ }^{13}$, destacando el denominado Plano de la zona siniestrada de Santander y parcelario aproximado elaborado por Eugenio Rioyo Gutiérrez, el que mejor ofrece una imagen del sector de ciudad destruido, pero sin embargo el parcelario se ha simplificado extraordinariamente, especialmente en los sectores más $\operatorname{conflictivos}^{14}$ (Fig. 3). Ha sido sin embargo sobre este plano, imperfecto en el detalle, sobre el que se han realizado posteriores estudios que arrastran por lo tanto algunos errores ${ }^{15}$.

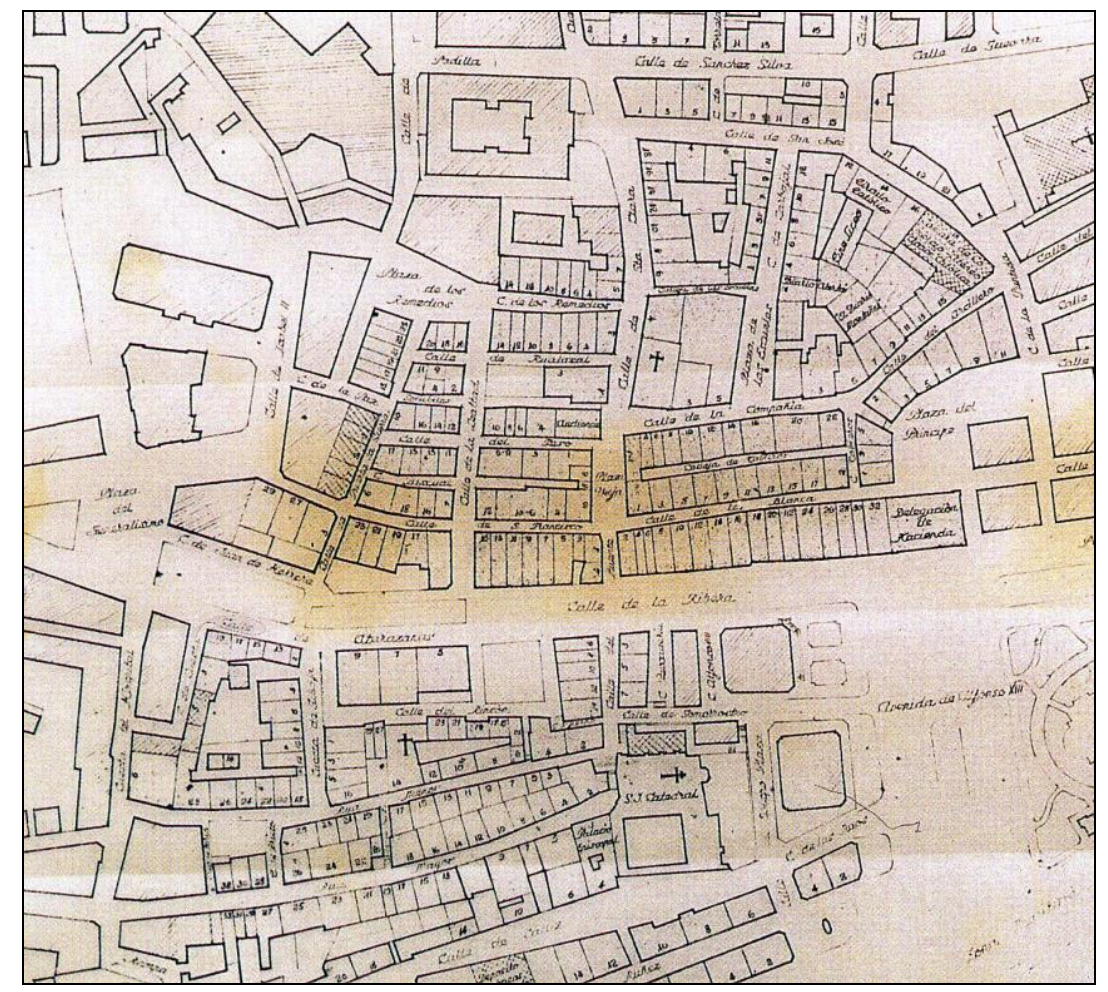

Fig. 3. Plano de la zona siniestrada de Santander y parcelario aproximado" elaborado por Eugenio Rioyo Gutiérrez, 1941 (Martín Latorre, 1998: 191). Ayuntamiento de Santander.

\footnotetext{
${ }^{13}$ El estudio del proceso ha sido abordado en Martín Latorre, De Meer Lecha-Marzo (2003: 45-58).

${ }^{14}$ Conservado en las oficinas técnicas municipales Sección Urbanismo, Publicado en (Martín Latorre, 1998: 191).

${ }^{15}$ Debe de ser sobre este plano que se realizaron las medidas de parcelas para el estudio de Fernández González, 2001.
} 
La planimetría realizada, algunos de cuyos detalles acompañan el texto, ha intentado reflejar todos los detalles que ofrecen las reconstrucciones de detalle de cada uno de los expedientes posteriores a Febrero de 1941. En ocasiones ha sido necesario recurrir a las fotografías de la ciudad tras el incendio. Las imágenes existentes son documentos de incalculable valor. Es preciso indicar aquí cuanto de nuestras representaciones parcelarias de la ciudad histórica parten del error de dibujar una línea de división de propiedades que choca con la realidad del modo de construir la ciudad histórica y especialmente medieval. En efecto lo que las fotografías nos muestran es una estructura construida de muros, en que algunos serían medianeros, mientras otros podrían pertenecer a una sola construcción. Todo ello aparece naturalmente simplificado en los planos parcelarios donde únicamente se dibuja una línea. La imagen de la ciudad tras el incendio ofrece sin embargo un paisaje de muros, que debe llevarse al modo convencional de representación de las líneas de división parcelaria (Fig. 8, 9 y 10).

\section{Interpretaciones del tejido viario y parcelario en el área intramuros occi- dental: de Santa Clara a San Francisco.}

Para el análisis del parcelario y de la morfología urbana del centro histórico de Santander, es de la mayor importancia el estudio y representación de la muralla medieval en el plano. Ha sido señalada repetidas veces la importancia de los muros medievales, que aquí se puede resumir en dos aspectos. Comoquiera que en la mayoría de los casos la muralla se plantea en los orígenes del desarrollo de la ciudad, el trazado de la cerca nos ofrece muy valiosas informaciones sobre la topografía original del lugar en que paulatinamente se desarrollará la ciudad bajomedieval. Por otra parte la dificultad técnica y económica que suponía la construcción de la cerca siempre condiciona su trazado, su tamaño, la decisión sobre las áreas que incluye o no, nos informan de cuál fue la idea de ciudad que aparece en el proyecto urbano tras el que se erige la muralla. Al respecto es especialmente significativa la existencia de irregularidades o quiebros en el trazado, que deben siempre justificarse en las características topográficas o en la preexistencia de elementos que justifican trazados "extraños". Finalmente una vez construidas las murallas, el trazado y la ocupación de las calles viene condicionada por ellas, tanto por la disposición de las puertas, como por la facilitad de trazar calles interiores al recinto que permiten el desarrollo adecuado de la vida urbana. 
En el caso concreto de la ciudad de Santander, varias son las anotaciones convenientes a este respecto. La muralla debió construirse en varias fases entre la fecha de 1187 en que es concedido el Fuero y las décadas posteriores, sin que dispongamos de ninguna noticia documental del proceso de construcción de las cercas ${ }^{16}$. Para la interpretación correcta del trazado del recinto amurallado la primera dificultad es la identificación de la topografía urbana en detalle del espacio en que se situarán Puebla vieja y nueva de la ciudad de Santander. Si la topografía general puede estudiarse a partir de los documentos existentes no sucede así con la micro-topografía; dada las especiales características de ubicación, la existencia de pequeñas elevaciones, rocas y peñas sobresalientes o manantiales debió condicionar los primeros asentamientos y la organización de la muralla.

\subsection{Huellas del trazado de la cerca.}

El análisis de los tejidos viarios y parcelarios en el extremo noroccidental del recinto amurallado medieval, entre la plaza de Los Remedios y la actual plaza del Ayuntamiento es del máximo interés. En la Planta reconstructiva elaborada se ha dibujado todo este sector con el máximo detalle posible, y ello ha permitido determinar con exactitud un tramo del trazado identificando un punto singular de este que hasta ahora había escapado a los distintos investigadores (Fig. 4).

Como ya se ha señalado más arriba, la mayoría de las reconstrucciones del trazado de la muralla medieval se han basado en los planos de Escofet de 1781 y de Colosía de 1790. A partir de esta información gráfica se ha representado sobre el plano la línea de muralla atendiendo a distintas circunstancias de detalle, siendo varias las zonas que merecen un estudio detallado.

En el sector del Instituto Santa Clara la muralla se ha hecho coincidir con la tapia del convento, incluida la zona de trazado curvo. A pesar de haberse señalado la existencia de un cubo en la muralla en esta zona, tal y como parece apreciarse en el grabado del siglo XVI a partir de los dibujos de Hoefnagel y publicado por Braun y Hogenberg, la ausencia de tal elemento en las representaciones gráficas de finales del siglo XIX ha aconsejado no considerarlo en el dibujo, sin que sepamos en qué momento pudo desaparecer, o si realmente, nunca llegó a existir tal cubo.

${ }^{16}$ Aproximación general al proceso en (Fernández González, 2001: 209). 
Fig. 4. Planta reconstructiva del centro histórico 1836-2016. Detalle sector convento de San Francisco, actual Plaza del Ayuntamiento.

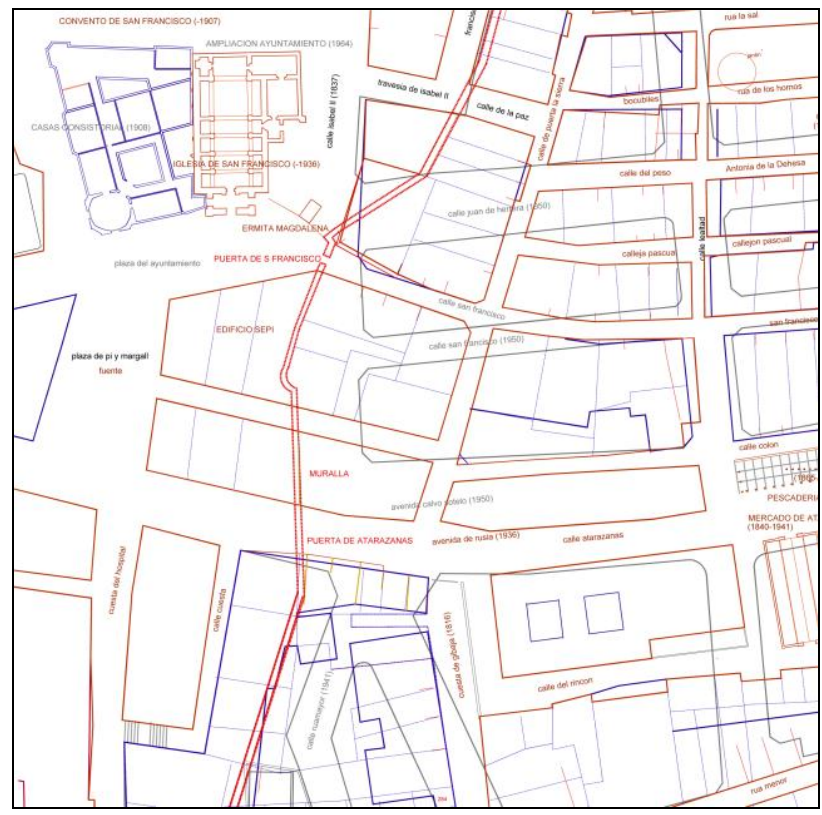

El tramo de muralla que desde el antiguo convento de Santa Clara discurre hacia el sur se ha dibujado a partir de la existencia de dos huellas del parcelario en que se conserva el primitivo trazado. La primera huella cierta se sitúa en la medianera oriental del que fue edificio de la calle de la Paz anteriormente al incendio de 1941, luego retomada en el no 1 de la calle Juan de Herrera tras la reconstrucción de la zona. Se conserva una fotografía en que se ha producido el derribo del edificio situado inmediatamente al sur, apreciándose la pervivencia del resto de la muralla, que había quedado como medianero (Sarabia Regina, 2003: 879).

El parcelario de origen medieval de esta zona había quedado ya alterado tras la apertura de la calle Isabel II, que debió comenzar en 1835. La mayoría del espacio ocupado por la nueva calle se trazó por los terrenos de huerta y cementerio del convento de San Francisco. En su lateral Este se fueron construyendo varios edificios; uno de los primeros, es el que apoyando su trasera en los restos de muralla formaba esquina con la denominada calle de la Paz, cuando años después se edifique aquí el noble edificio que albergará los Almacenes El Águila ya se alinea con el existente más al norte marcando con claridad la alineación de la calle Isabel II. La construcción de este edificio conllevó el derribo de un tramo de muralla que podemos suponer se habría con- 
servado como límite trasero de las edificaciones de Puerta la Sierra hacia el convento, trazándose un solar regular, con una nueva alineación del tramo final de San Francisco.

Inmediatamente al sur, la interpretación del parcelario anterior al incendio ha permitido identificar un nuevo punto fijo del trazado, inédito hasta el momento; la medianera oriental del que fue edificio Sepi, situado en el espacio que hoy es plaza del Ayuntamiento, marca con exactitud la línea de muralla. Tal se deduce de dos documentos gráficos de los años 40 del siglo XX. En los planos de Agustín de Colosía aparece en esta zona un muro en curva, que vuelve a aparecer en el parcelario realizado con motivo de la subasta de solares $^{17}$, estando ausente sin embargo en el plano de 1941 Plano de la zona siniestrada (Fig.5).

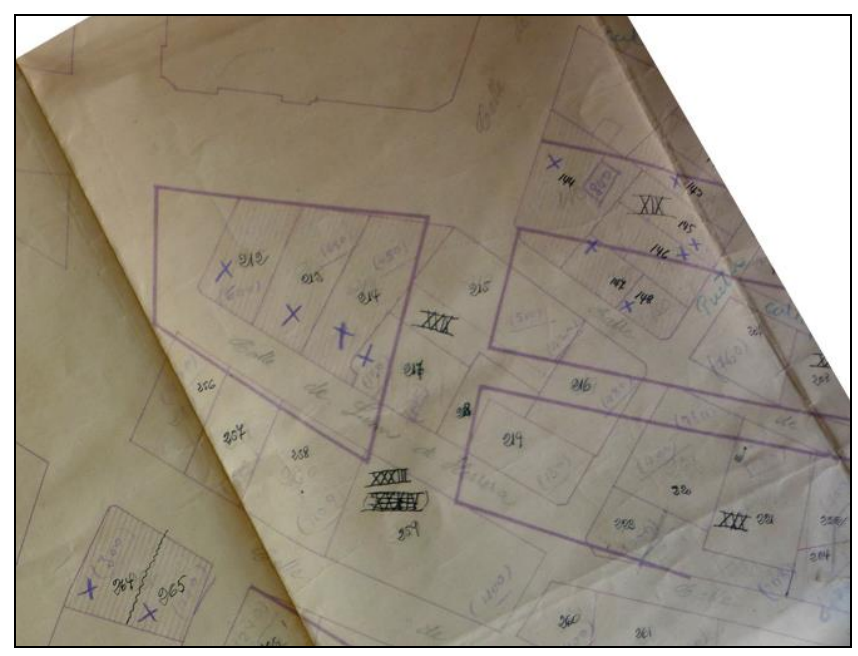

Fig. 5. Plano parcelario para la reconstrucción del área siniestrada. 1941. Detalle área Plaza del Ayuntamiento con manzana edificio Sepi. (Archivo Municipal de Santander. s/r).

El trazado del muro vuelve a hacerse evidente con motivo del derribo del edificio Sepi, realizado en 1962-1963, apreciándose la forma cóncava de la medianera en las fotos conservadas, testigo último de la antigua existencia de la pequeña curva de la muralla ${ }^{18}$. Por desgracia en dichas fotos no es posible comprobar si para la fecha existía algún resto del muro embutido en la medianera, que debería presentar un perfil similar al detectado más al norte en la medianera al final de la calle Juna de Herrera. (Fig. 6)

\footnotetext{
${ }^{17}$ Archivo Municipal de Santander, 1941, s/r.

${ }^{18}$ Fotos del derribo en Santander Historia gráfica de la ciudad (1984: 89 y 94). Cobo de la Hera, p. 91 y p. 188.
} 


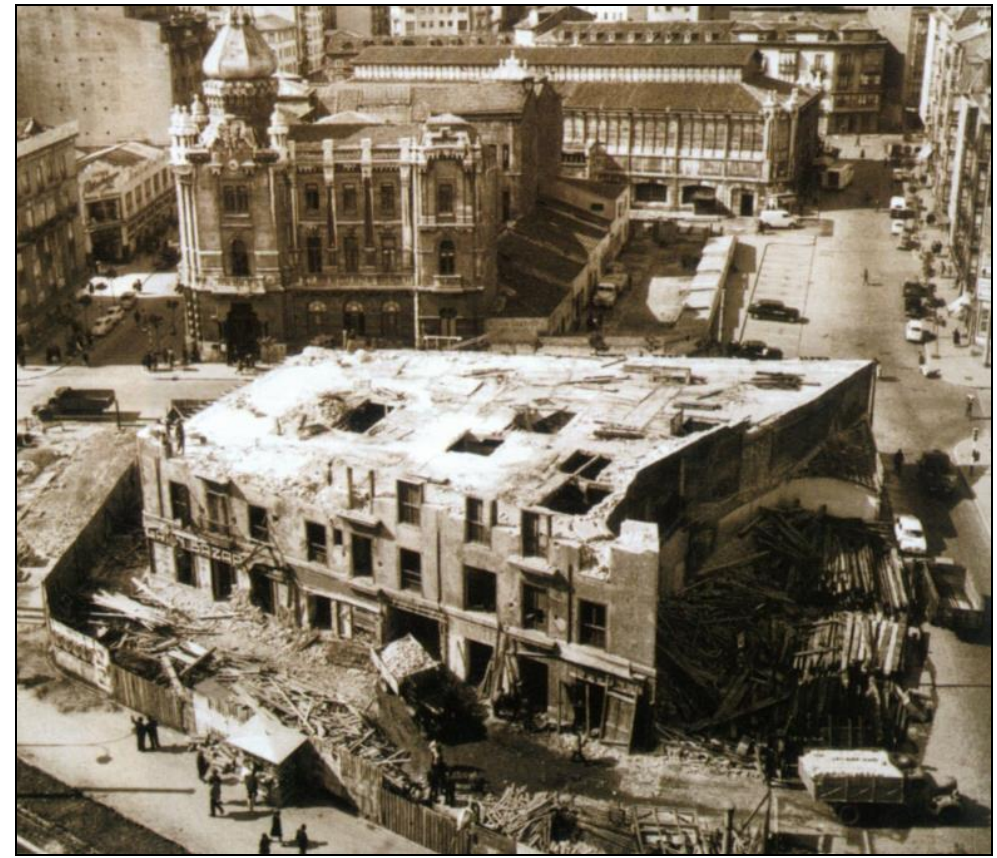

Fig. 6. Antigua manzana de Almacenes Sepi, durante su derribo, apreciándose la medianera con la singular solución cóncava determinada por la cerca medieval. (Cobo de la Hera, p. 188). Colección Thomas/CDIS.

La existencia de este singular punto de quiebro resulta de difícil interpretación y no ha sido abordada hasta el momento; es posible aventurar dos hipótesis. La primera haría referencia a la existencia de una roca o peña en el lugar, y al lento proceso de construcción de la muralla, que daría pie a desajustes en la alineación; pero es posible plantear una segunda, y es que tal como aparece trazada la curva es posible aventurar la existencia de una solución de encuentro con un muro que recogería la forma de la puebla nueva en su límite sur, en paralelo al trazado del arroyo de Becedo. Sobre la existencia de tal cerca no poseemos ninguna noticia, y siempre se ha dibujado un circuito amurallado unitario para el conjunto de las pueblas vieja y nueva, pero sin duda obedece a una cierta lógica. Conocemos la existencia de una cerca similar en el caso de la puebla de Laredo, inmediatamente al sur de la calle Rúayusera, dando hacia el sur al cauce del arroyo Bario, que en una segunda fase se abandona a favor de una cerca unitaria una vez desarrollado el Arrabal de Cordoneros (Remolina, 2001: 99). 


\subsection{Las huellas de los dos conventos.}

Especial interés presenta el estudio de las superposiciones históricas representadas en la Planta reconstructiva en la zona de Santa Clara. El plano presenta por primera vez la superposición de las construcciones del convento de Santa Clara, tal y como estas habían llegado al último cuarto del siglo XVIII y las estructuras actuales. El convento debió fundarse en el siglo XIV, con reformas en la Edad Moderna, y desde el primer cuarto del siglo XIX albergó un centro de enseñanza.

El estado anterior a 1838 sólo puede ser estudiado a través de las representaciones aparecidas en los planos de Juan Escofet y Agustín de Colosia, publicados en 1780 y 1791, los primeros que muestran con detalle la organización real de las edificaciones, afortunadamente ambas de un gran rigor a pesar de la escala de representación. La finca del convento aparece con varias construcciones, que deben proceder de distintas épocas; la grafía con doble línea debe señalar las principales edificaciones tal y como vemos en las iglesias de la Compañía y de San Francisco. Se señalan así en Santa Clara dos volúmenes, el sur es el dedicado a capilla, donde se señala la existencia del ábside. Adosado al norte se sitúa otro volumen compacto, tal vez dependencias anejas antiguas. En 1916 se construyó el edificio de aire clasicista que aún hoy existe, conllevando la destrucción de los últimos restos del antiguo convento.

El Convento de San Francisco se situaba extramuros, inmediatamente al oeste del tramo de muralla antes estudiado. Cuando a finales del siglo XIX el Ayuntamiento decide ocupar el espacio para la construcción de una nueva Casa Consistorial, solo se procederá al derribo del claustro y dependencias anejas, construyéndose entre 1899 y 1907 el cuerpo occidental, adosado a la iglesia ${ }^{19}$. En la Planta reconstructiva del centro histórico se ha dibujado el nuevo Ayuntamiento con su medianera perfectamente adosada a la línea exterior del templo del convento, existiendo un problema de encuentro entre la esquina sureste del nuevo edificio y el porche de la iglesia conventual, que no se resolvió hasta el derribo del templo en 1936 y la posterior ampliación de la Casa Consistorial.

${ }^{19}$ El Ayuntamiento es un proyecto de 1897-1907 de Julio Martínez Zapata y Rodríguez. 


\section{Reconstrucción del parcelario y el tejido viario históricos en el área orien- tal de la puebla.}

El tejido viario de la denominada Puebla nueva es con seguridad el resultado de la aplicación de un proyecto urbano previo, ejecutado a partir de la concesión de fuero a la villa por Alfonso VIII en 1187, que busca establecer una puebla planificada frente al viejo asentamiento nacido en torno a la abadía de los Cuerpos Santos. Se ha señalado el paralelismo entre el tejido planteado en la puebla santanderina y el de la puebla de Laredo, dotada esta de fuero en 1200 (Remolina Seivane, 2006: 105); efectivamente en ambos casos se trata de un trazado de tres calles principales en sentido norte-sur, completado con la apertura de tres transversales, hasta crear una estructura aproximadamente ortogonal.

En paralelo a la planificación de la puebla debió trazarse la muralla, que sin embargo abarca una extensión mucho mayor, extendiéndose hacia el este. Los resultados de la reciente excavación arqueológica de la Plaza Porticada han confirmado la antigüedad de este extremo oriental de la cerca, datado desde finales del siglo XII a mediados del XIII, así como la previa existencia de una rampa de acceso a la pequeña playa que aquí existió, coincidente con el callejón que existió hasta 1941, la rampa de Arcillero $^{20}$.

Se confirma así la existencia de una mínima infraestructura portuaria en la zona anterior a la concesión del fuero, permitiendo justificar la gran amplitud del recinto cercado con respecto a la puebla planificada, que sólo ocupa la mitad occidental del espacio intramuros, en la conveniencia de incluir dentro del recinto esta pre-existencia altomedieval.

El trazado de la cerca habría buscado así incluir el área funcionalmente más interesante, la situada al oeste, donde se trazarán las tres calles, pero también los elementos anteriores al fuero: el pequeño asentamiento del Arcillero y la colina situada sobre la dársena, donde posteriormente se edificaría la Torre de Don Gutierre, una de las primeras casas torre de que tenemos constancia.

El posterior desarrollo de la puebla vería interrumpido su dinamismo en los siglos posteriores, y el área nororiental nunca llegaría a ocuparse, dedicándose a actividades agrarias. Sólo a partir del siglo XVII el área se urbanizará, tras la

\footnotetext{
${ }^{20}$ Véase una primera presentación de resultados en (Iglesias Gil, 2008: 274-277).
} 
instalación del convento de la Compañía de Jesús, edificado en vecindad con la Plaza Vieja, abriéndose calles que estructurarán este gran vacío urbano.

Sabemos además de la temprana existencia de una alhóndiga, que los documentos denominan Palacio del Trigo, situada seguramente junto al lugar donde luego se construyó la Casa Consistorial a mediados del siglo XVII; otras destacadas construcciones fueron el Palacio de Riva Herrera, construido a partir de 1605, y las torres de Escalante de la calle Palacio (Fernández González, 2001: 273, 285, 482).

El parcelario que se ha dibujado en la planta reconstructiva, refleja el estado a mediados del siglo XIX, y por ello apenas permite una interpretación de lo que pudo ser la partición catastral medieval en el área ${ }^{21}$ (Fig.7).

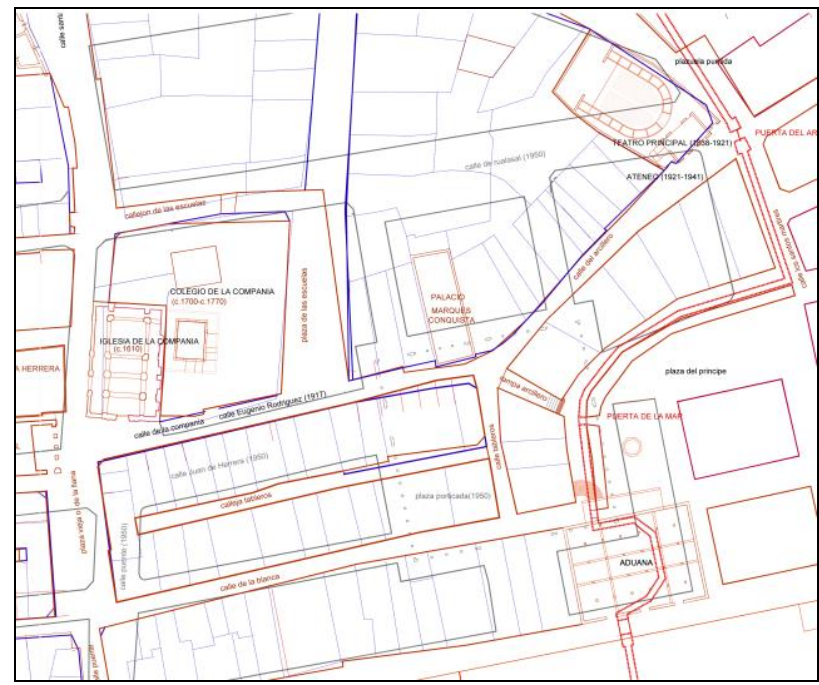

Fig. 7. Planta reconstructiva del centro histórico 1836-2016. Detalle sector Plaza del Príncipe.

\section{1. Área de la plaza del Príncipe.}

Hacia el Este se situaba un área morfológicamente muy interesante, caracterizada por la muralla del siglo XII-XIII, y por las preexistencias relacionadas con la topografía y la inmediata ensenada donde se situará la Plaza del Príncipe. El plano de Pérez de Rozas, el primero que representa las variaciones orográficas según curvas de nivel en la ciudad, señala la existencia de una importante elevación en el tramo final de la calle La Blanca. Esta elevación poseería

\footnotetext{
${ }^{21}$ Véase el intento de reconstrucción en (Fernández González, 2001: 420 y ss).
} 
un importante carácter estratégico, enfrentada a la elevación de Somorrostro donde se situaba la abadía de los Cuerpos Santos y donde se levantó el castillo de San Felipe. Evidentemente el desarrollo urbano hasta la mitad del siglo XIX habría conducido a la eliminación de las variaciones topográficas bruscas, de tal manera que lo que debieron ser fuertes contrastes se irían suavizando. El estudio de esta micro-topografía es sin embargo muy significativa y en las escasas fotografías conservadas de las calles de San Francisco y la Blanca antes del incendio aparece claramente esta singularidad: nunca fueron calles llanas, sino que poseían una ligera pendiente, descendiendo la calle San Francisco desde el oeste hasta su encuentro con la plaza Vieja, para desde aquí, ahora denominada calle de la Blanca, ascender suavemente hasta la mitad de su trazado, y nuevamente descender hacia la plaza del Príncipe, donde siempre fue preciso la disposición de rampas o escaleras de descenso al nivel de esta plaza (Fig.8).

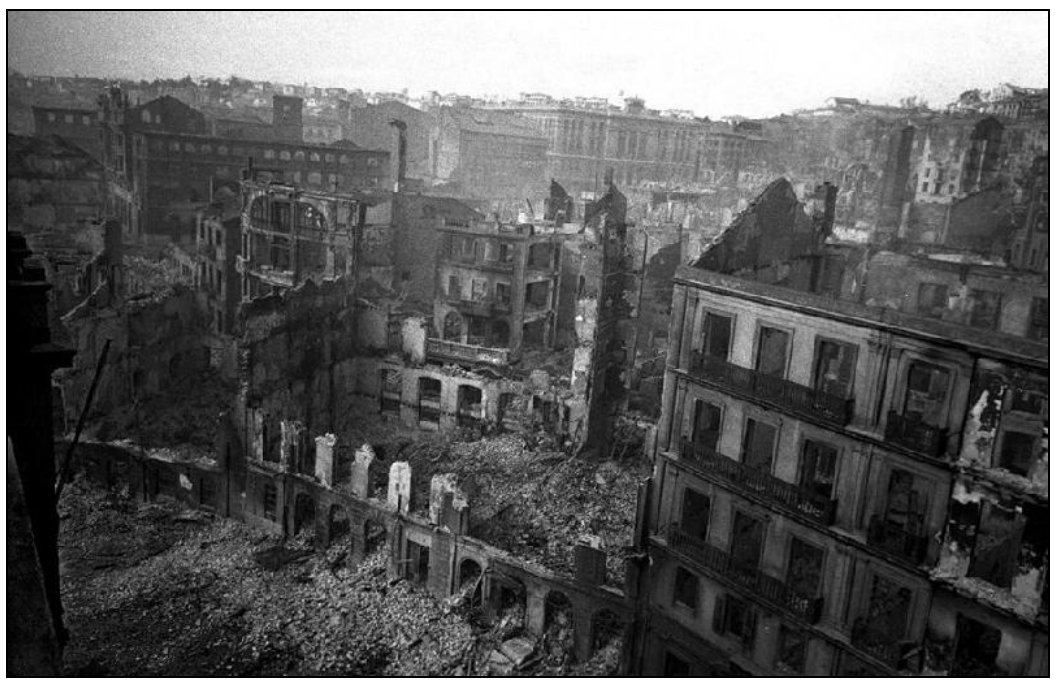

Fig. 8. Plaza del Príncipe y rampa Arcillero tras el incendio de Febrero de 1941 y las posteriores demoliciones. (Cobo de la Hera, 2016: 121), Colección Víctor del Campo Cruz/CDIS.

La reconstrucción del parcelario antiguo en esta área ha sido especialmente dificultosa, debido a las irregularidades que presenta. El trazado de la calles del Arcillero y Tableros y de la rampa de Arcillero serían así anteriores al trazado de la cerca, abiertas de acuerdo a la topografía de la zona ${ }^{22}$. Enseguida se edificaron

22 Véase la descripción de las calles anteriores al incendio en (Simón Cabarga, 2001b: 44, 143). 
aquí las casas torre de las más importantes familias de la villa, en la esquina de Arcillero con La Blanca se situó la casa torre de Escalante y un poco más al norte la de Agüero (Casado Soto, 1997b: 91). La muralla no se situó en la cota más alta, sino al pie de esta, a la altura del playón aquí existente; entre la que suponemos abrupta ladera y la muralla se abría la que fue denominada calle de la red Chica o calle Chiquita ${ }^{23}$. Los planos del siglo XVIII muestran una hilera de casas adosada por el exterior de la muralla, de una sola planta, que serían derribadas con los últimos restos de la muralla en la zona entre 1833 y $1865^{24}$.

En la zona debieron situarse varias casas torre, sin que se haya podido ubicar con exactitud cada una de ellas en el plano. Sí es segura la ubicación de la torre de Don Gutierre, cuyos restos se han localizado en las excavaciones de la Plaza Porticada (casa haciendo esquina entre calle La Blanca, calle Tableros, calleja Red Chica), ocupando por tanto un lugar destacadísimo en la topografía de la Puebla Nueva (Fernández González, 2001: 480, 483).

La gran torre con cubos que aparece en la representación del siglo XVI, de Joris Hoefnagel, publicada por Braun (Casado Soto, 1990: 40), debió situarse precisamente en la manzana entre la calle Tableros y la ladera, de tal modo que los grandes cubos actuarían a modo de contrafuertes traseros hacia la dársena, una solución que también aparecerá en la trasera de otras casas torre de la Rúa Mayor. En el dibujo además parece apreciarse el cambio brusco de alineación con respecto a las pequeñas casas y parcelas inmediatamente al este, tal y como es posible apreciar en la reconstrucción del parcelario anterior a 1941. Por otra parte en el cantón de encuentro de las calles Tableros y Arcillero con la rampa, se situó la única casa torre de la que conservamos documentación gráfica, ya convertido en palacio en el siglo XVII-XVIII, perfectamente identificable en las fotografías posteriores al incendio, el palacio del Marqués de la Conquista, que en el plano de 1865 aparece saliente con respecto a las edificaciones vecinas, marcando otra vez un punto de ruptura de la orientación del parcelario ${ }^{25}$.

\footnotetext{
${ }^{23}$ Cfr. (Fernández González, 2001:280), tal vez las menciones se refieran a dos callejuelas distintas.

${ }^{24}$ Un plano de 1833 aún dibuja estas casas de una planta (Casado Soto 1997b: 91); el plano de Pérez de Rozas ya no las recoge.

${ }^{25}$ Los escudos fueron estudiados en (González Echegaray, 2000: 38, fig. 32-33) y (Aramburu Zabala, 2001: 267).
} 


\subsection{Frente de la Ribera: parcelario.}

El área denominada de la Ribera constituía un gran frente edificado orientado hacia el sur, enfrentado a la dársena portuaria. Fue siempre un lugar de gran vitalidad urbana. Ya en el siglo XVII debía presentar la parcelación estrecha y profunda característica de los lugares más centrales de la ciudad medieval. La descripción urbana del clérigo Zuyer, en 1669, señala la existencia de 26 casas, número que viene a coincidir con las parcelas que presenta la alineación en tiempos del plano de Pérez de Rozas (Simón Cabarga, 2001b: 112). Se posee documentación gráfica de algunos solares situados en la zona entre las calles San Francisco y Atarazanas, en el siglo XVIII, que nos muestran un parcelario estrecho y alargado (Casado Soto, 1997b: 72).

Un documento de 1803 nos ofrece una interesante imagen del frente edificado, en que coexisten casas de dos plantas con patio delantero, con casas de cuatro niveles, recién edificadas, que poco a poco irán sustituyendo a las antiguas construcciones. En las primeras representaciones gráficas que tenemos aparecen componiendo el frente edificado numerosas viviendas en altura, de estrechísima fachada, con apenas dos huecos y gran profundidad, cuyas parcelas van siendo paulatinamente unificadas para permitir la edificación de casas más modernas. En las primeras fotos disponibles, datadas en 1880, se conservan hasta seis de estas edificaciones, que posteriormente serían derribadas para dar lugar a la edificación de inmuebles colectivos más modernos, de tal modo que en 1941 únicamente quedaban dos construcciones antiguas, las llamadas casas de los pájaros, situadas junto a la calle del Puente, de las que conservamos numerosas imágenes que nos permiten estudiar perfectamente sus características formales.

Es de señalar el fuerte desnivel existente entre las fachadas delanteras y traseras de estas casas. El mismo plano de 1803 nos muestra con claridad el hecho: las viviendas representadas poseen cinco plantas más desván hacia el sur, y solo cuatro plantas hacia la calle San Francisco al norte. La existencia de un a modo de escalón central en la manzana se hizo evidente con motivo del incendio de 1941. Las fotografías posteriores al desescombro nos muestran el fuerte desnivel, que sería eliminado en la reconstrucción del sector urbano destruido, en los años inmediatamente posteriores ${ }^{26}$ (Fig.9).

\footnotetext{
26 Véanse imágenes en (Cobo de la Hera, 2016: 69, 195).
} 


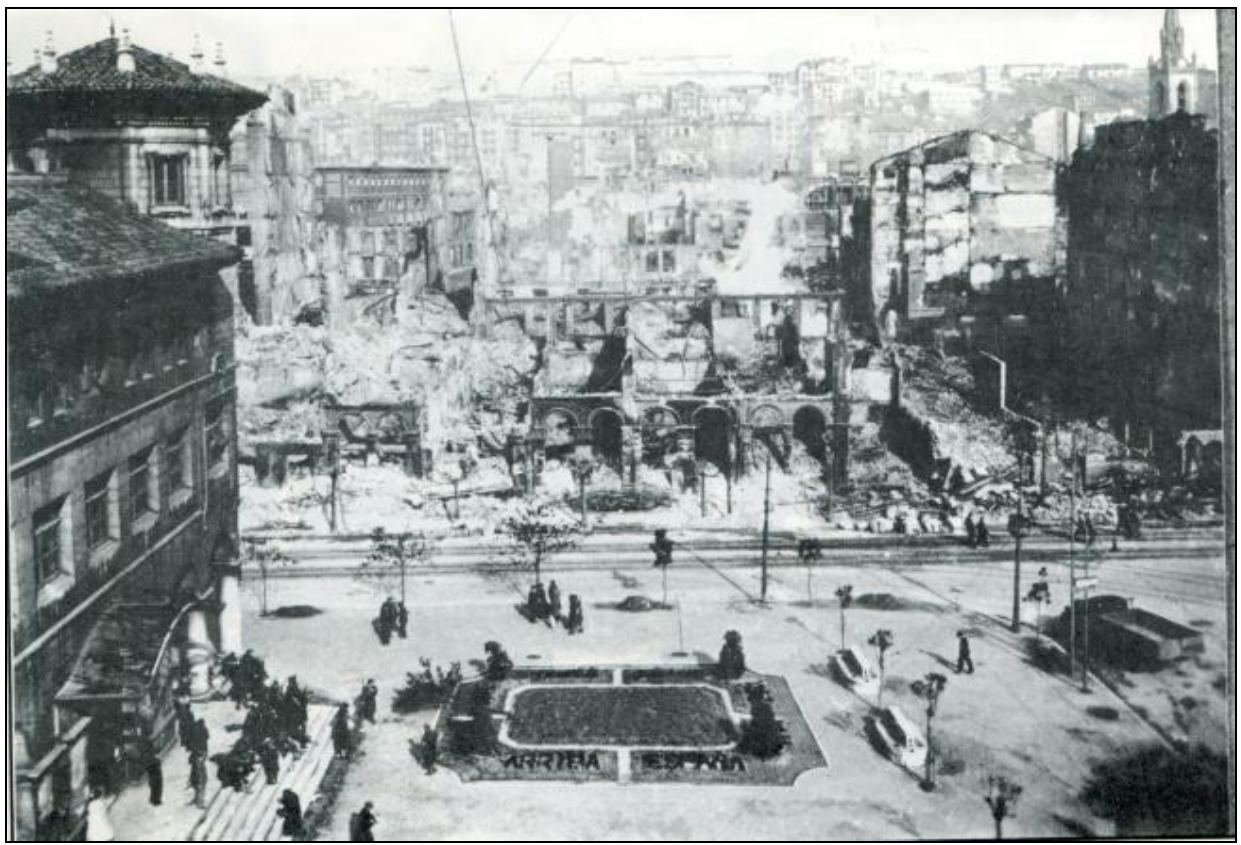

Fig. 9. La Ribera tras el incendio de Febrero de 1941 y las posteriores demoliciones. Foto Colección Foto Samot / El Diario Montañés.

\section{Al norte de la Puebla: Manzana de la Compañía de Jesús, área de la calle San José.}

Junto a la Plaza Vieja se fundó a partir de 1603 un convento de la Compañía de Jesús, pieza fundamental en el desarrollo urbano de esta área. Debió existir una cierta dificultad para encajar la iglesia en la trama parcelaria solicitándose permiso en 1607 para ocupar parte de la calle Santa Clara, que debía poseer un trazado un poco más curvilíneo. La orientación de la iglesia con la fachada hacia el sur debe obedecer a la voluntad de hacerse presente en la Plaza Vieja, la principal de la ciudad, pero también a la dificultad inicial de disponer de más espacio.

En el plano se han representado los claustros que existieron junto a la iglesia de la Compañía. En 1769 se produce la expulsión de los jesuitas, que se ven obligados a abandonar el convento; parte de la manzana debió entonces parcelarse puesto que en la primera década del siglo $X X$ se edifica junto a la iglesia el edificio ecléctico de los almacenes Pérez del Molino. 
En torno a 1814 se abrió junto al convento la denominada plaza de las Escuelas (Simón Cabarga, 2001: 72). En el plano de Colosía de 1790 existe un callejón lateral muy secundario, al que en algún momento indeterminado se decide ampliar la anchura. La ampliación se realiza a partir de la creación de una crujía de edificación, en que se instalaron las primeras escuelas de la ciudad. De la organización interior de la manzana poco sabemos, pues el interior se representa como edificado, pero sin mas cualificación que la existencia de los dos claustros.

\subsection{Traslacava y nueva calle San José.}

Zona asimismo de gran interés es la situada en el extremo nordeste de la puebla nueva, entre la Calle Santa Clara y la Plaza del Príncipe. Junto al convento de Santa Clara se abrió la Puerta del mismo nombre, que daba salida hacia los barrios situados al norte de la ciudad. Monte, Cueto, etc. Hacia el oeste la muralla presentaba una curva continua hasta llegar a la Puerta del Arcillero. En este sector la decisión de derribar la muralla se acompaña de la urbanización del antiguo camino de Traslacava, que dará lugar a la denominada calle de San José, fundamental eje viario articulador de la zona ${ }^{27}$.

El camino denominado Traslacava ya aparece con un cierto carácter urbano en los primeros planos, al menos en su primer tramo. En efecto en el plano de 1780 de Juan Escofet y en el de 1781 de Francisco Sabatini, se aprecia la existencia del frente norte de la futura calle, formando un rincón que permanecerá hasta su desaparición en 1941. En los planos de mediados del siglo XIX se aprecia con claridad la importancia concedida a la nueva calle ${ }^{28}$; en la esquina se instalará en 1839 el Teatro Principal, que define la que será definitivamente la alineación de la nueva calle. A partir de este trazado de la calle se plantea en 1914-16 el proyecto de nuevo Instituto Santa Clara, valorando el eje de esta con la gran escalinata y el diseño de pabellón central.

Toda esta zona situada entre las calles Compañia y Arcillero y la cerca hacia el norte, debió presentar históricamente un carácter rural, con numerosas

\footnotetext{
${ }^{27}$ La apertura de la calle debe coincidir con la política de reformas urbanas planteada por José de Peterrade, maestro de obras municipal en 1822, quien elaboró un plano de ellos en 1821. (Sazatornil Ruiz, 2016: 254), (Simón Cabarga, 2001a: 434) y (Simón Cabarga, 2001b: 130-131).

${ }^{28}$ Entre los más destacados cabe citar el realizado por Francisco de Coello, hacia 1860 (Martín Latorre, 1998: 100).
} 
huertas. La urbanización de la calle San José iba a propiciar el sucesivo desarrollo del área, planificado en la época de Atilano Rodríguez Collado, que fue arquitecto municipal entre 1870 y 1892 y planteó el desarrollo del denominado prado de Tantín, con la apertura de viales que habrían de incorporar este espacio a la trama urbana (Simón Cabarga, 2001a: 439).

\section{Reconstrucción del parcelario y tejido histórico en área de la Cuesta de Gibaja.}

$\mathrm{Al}$ sur de la antigua calle Atarazanas, más o menos coincidente con la actual calle de Calvo Sotelo, se situaba antes del incendio de 1941 la Cuesta de Gibaja, importante acceso al conglomerado de calles de la puebla alta; aquí se hace mucho más difícil identificar con exactitud el parcelario histórico y, sobre él, el trazado de la antigua cerca, debido a las transformaciones sufridas en el área alrededor de la mitad del siglo XIX. El análisis del parcelario solo permite situar con una cierta aproximación el punto de quiebro de la muralla tras la fachada sur de calle Atarazanas, pero queda dudosa su huella en la división parcelaria de la manzana, y no se puede identificar con claridad la línea exacta por la que subía la ladera.

La apertura de la cuesta de Gibaja fue una singular operación de transformación de los tejidos urbanos de la zona, emprendida en los primeros años del siglo XIX por el comerciante Francisco de Gibaja, llevándose a cabo la edificación entonces del frente de casas situadas en el margen oeste de la cuesta, con la creación un importante muro de contención, que permitía discurrir a nivel más bajo la calle Rincón (Simón Cabarga, 2001b, 73). Inmediatamente, al este se construyó la gran manzana de viviendas del no 3 de Atarazanas, con tres solares de diferentes dimensiones, pero resultando una edificación de cinco alturas muy homogénea. Este edificio es el que aparece como una de las imágenes más significativas de la calle Atarazanas tras el incendio de 1941; sus muros de carga resistieron al fuego, derrumbándose totalmente el interior. En los días sucesivos al incendio se debió derribar su fachada a Atarazanas, por problemas de estabilidad, permaneciendo sin embargo durante un tiempo indefinido los muros interiores que daban a los dos pequeños patios de manzana ${ }^{29}$ (Fig.10).

\footnotetext{
${ }^{29}$ La fachada aún se mantiene en pie en la foto publicada (Cobo de la Hera, 2016: 70). Fotografía muy significativa, tras el derribo de la fachada, en (Casado Soto, 2001: 98-99).
} 


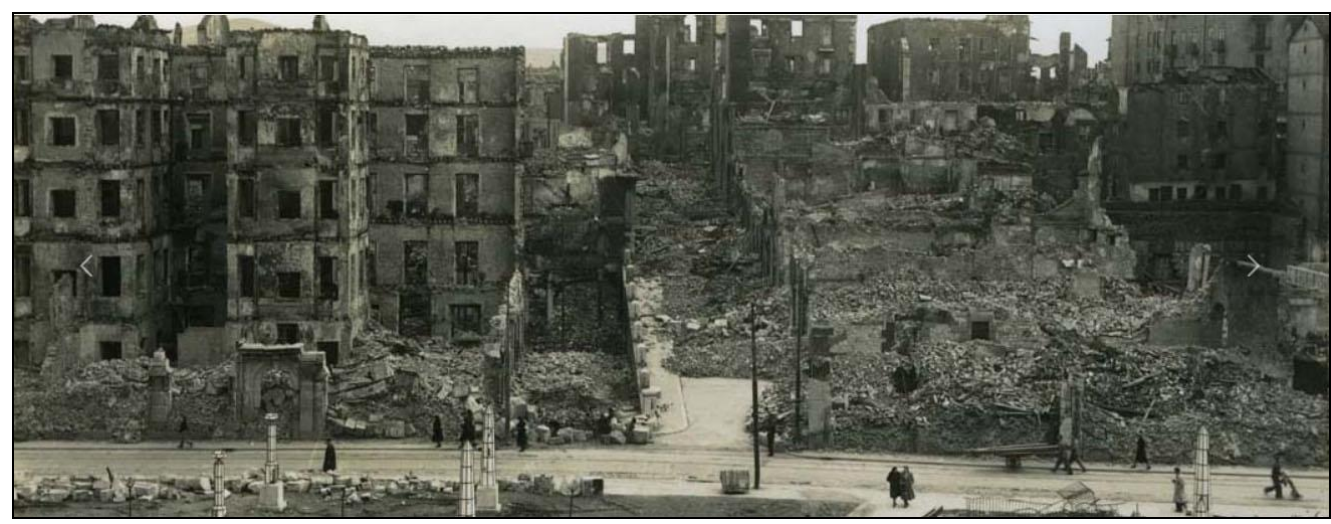

Fig. 10. Cuesta de Gibaja tras el incendio de Febrero de 1941 y las posteriores demoliciones. (Cobo De La Herab 2016b: 109), Fondo Arauna/CDIS-Archivo ABC.

La calle Cuesta, un callejón sin salida, a nivel más bajo que las calles de su alrededor, aparece por primera vez representada en el primer plano de Escofet como callejón exterior y paralelo a la muralla, cercano al hospital. Según señala Simón Cabarga la calle adquiere importancia en 1845, edificándose nuevas viviendas en los años posteriores ${ }^{30}$. Debe ser con motivo del desarrollo de estos dos sectores que se producen alteraciones radicales de la trama parcelaria medieval, con amortización de lo que quedaba de muralla, alterándose la topografía y el parcelario.

Como quiera que ninguno de los planos detallados de la zona, ni siquiera el de Pérez de Rozas, dibuja con claridad la geometría del parcelario en el interior de la manzana, se hace imposible la reconstrucción exacta de la línea de la muralla. Ni siquiera las fotografías del área posteriores al incendio nos ofrecen pistas seguras: la gran panorámica realizada desde la Catedral en 1946 muestras las traseras aun en pie sin que podamos identificar estructura antigua destacada alguna (Cobo de la Hera, 2016: 211).

Para la situación exacta del trazado de la cerca y de la puerta situada al final de la Rúa Mayor sólo puede servir de ayuda el análisis del parcelario de la manzana situada entre Cuesta del Hospital, Rúa Menor y Rúa Mayor, que no desapareció con el incendio y se ha conservado parcialmente. La división parcelaria interna de la manzana presenta una irregularidad notable, en cuya

${ }^{30}$ (Simón Cabarga, 2001b: 229); sobre la Rampa de Sotileza ver (Simón Cabarga, 2001a: 330). 
lectura pueden seguirse dos líneas posibles de identificación del trazado de la cerca: la línea curva que limita posteriormente los edificios con fachada a la calle Cuesta del Hospital, o la línea sensiblemente recta que divide la manzana internamente un poco más hacia el este. Si este trazado se confirma, la excavación de los cimientos del Cine los Ángeles, sin duda dejaría en evidencia la posible existencia de algún tipo de estructura, pero hasta el momento no se dispone de reportaje fotográfico hecho público del transcurso de estas obras ${ }^{31}$.

\section{Conclusiones.}

La elaboración de la Planta reconstructiva del centro histórico de la ciudad, se ha realizado con la intención de reflejar la estructura viaria y parcelaria urbana anterior al incendio de 1941, habiendo permitido profundizar en el conocimiento de los procesos de crecimiento de la ciudad de Santander en época medieval y moderna. Cuando las circunstancias históricas han hecho desaparecer la posibilidad de la investigación arqueológica del subsuelo, la herramienta de la lectura crítica del parcelario y los tejidos viarios puede aportar una última posibilidad de profundización en el conocimiento de los episodios históricos de construcción de la forma urbana. Del acercamiento realizado en este artículo han quedado al margen otras interesantes zonas urbanas, como la Rúa Mayor y el entorno inmediato de la Catedral, origen de la ciudad, cuyo análisis específico deberá realizarse a partir de una minuciosa lectura de toda huella física existente, y de recomposición crítica a partir del análisis del material gráfico histórico conservado.

\section{Bibliografía.}

CADINU, Marco (2012)." I catasti e la storia del luoghi: un progetto di ricerca ancora aperto" en CADINU, Marco (coord), I catasti e la storia dei luoghi. Cadastres and history of places, in «Storia dell'Urbanistica. Annuario nazionale di storia della città e del territorio», anno XXXI, Serie Terza, 4, 2012, edizioni Kappa, Roma, pp. 47-66.

CASADO SOTO, José Luis y otros (1979): La Crisis del siglo XVI, Cantabria a través de su historia, 9. Institución Cultural de Cantabria, Santander 1979.

\footnotetext{
${ }^{31}$ El cine fue edificado entre 1955 y 1957 según proyecto del arquitecto Francisco de Asís Cabrero.
} 
CASADO SOTO, José Luis (1990): Santander una villa marinera en el siglo XVI, Estudio, Santander.

(Ed) (1997a): La catedral de Santander Patrimonio monumental, Fundación Botín, Santander.

(1997b): La imagen de Cantabria en el Archivo de la Real Chancillería de Valladolid, Fundación Santillana, Madrid. (2001): El incendio de Santander, Santander.

Cово De LA HeRA, Teresa (coor.) (2016): 1941. Arde Santander, Entretiempos, Ed Cantabria, Santander.

FERNÁNDEZ GONZÁLEZ, Lorena (2001), Santander una ciudad medieval, Estudio, Santander.

GONZÁLEZ RIANCHO FRANCOS, Gabriel (2006): Santander, las imágenes y su historia, 2006, Ayuntamiento de Santander.

GONZÁlez EchegARAY, Carmen (2000): Escudos de Cantabria, Asturias de Santillana, I, Estudio, Santander.

GUIDONI, Enrico (2006): “Le piante ricostruttive di città. Inquadramento generale e metodológico" en COLLETTA, Teresa, Le piante ricostruttive del tessuti urbani medeivali e moderni, Kappa, Roma.

IGLESIAS GIL, José Manuel (2008), “La aplicación de los sistemas de información geográfica a la arqueología urbana", en Actas de los XVIII Cursos Monográficos sobre el Patrimonio Histórico, Universidad de Cantabria, pp. 265- 281.

MadariagA, Benito; Valbuena, Celia (1971): El Instituto de Santander, Santander.

MARTín LATORRE, Elena (Dir.)(1998): La memoria del territorio, Atlas histórico de Santander y su puerto, Autoridad Portuaria, Santander.

MARTín LATORRE, Elena; MEER LeCHA-MARZO, Ángela de, (2003): Evolución urbanística de Santander 1941-1990, Universidad de Cantabria, Santander.

PASSINI, Jean, Coor (2001): La ciudad medieval: de la casa la tejido urbano, Universidad de Castilla La Mancha, Cuenca.

PÉREZ SÁnCHEZ, José Luis. (Dir.) (2002), Crónica de Cien Años 1902/2002, El Diario Montañés, Santander.

POZUETA ECHAVARRI, Julio (Dir.) (1985), Santander el puerto y su historia, Junta del Puerto MOPU, Santander. 
Remolina SeIVAne, José Miguel (2001) "La Ciudad histórica de Laredo", en Villas al Mar Litoral Atlántico, nº 3, pp. 96-103.

Remolina SeIVAne, José Miguel (2006) "Las Villas nuevas medievales de Cantabria" en MARTíneZ SoPEnA, Pascual y URTEAGA, Mertxe (eds) Las Villas Nuevas medievales del suroeste europeo, Boletín Arkeolan 14, 2006: 99-114.

RODRIGUEZ LLERA, Ramón (1980), La reconstrucción urbana de Santander 19411950, CEM, ICC, Santander.

SANTANDER Historia gráfica de la ciudad, II (1984) Ayuntamiento de Santander, Santander.

SARABIA ReginA, Pedro (2003), “Estudio de las estructuras arqueológicas localizadas en el solar del Cine Coliseum (Santander)", en FERNÁNDEZ IBÁÑEZ, Carmelo, RuIZ COBO, Jesús, (Eds.), La arqueología de la bahía de Santander, Fundación Botín, Santander, pp. 865-879.

SAZATORNIL RUIZ, Luis (1996) Arquitectura y desarrollo urbano en Cantabria siglo XIX., Universidad de Cantabria, Santander 1996

SIMÓN CABARGA, José (2001a): Santander. Biografía de una ciudad (Edición 1954), Estudio, Santander

SIMÓN CABARGA, José (2001b): Santander en la historia de sus calles (1ª edición 1980), Estudio, Santander. 